\title{
Modelling seasonal nutrient inputs from non-point sources across large catchments of importance to aquaculture
}

\author{
Lynne Falconer*1, Trevor C. Telfer ${ }^{1}$, Lindsay G. Ross ${ }^{1}$
}

${ }^{1}$ Institute of Aquaculture, University of Stirling, Stirling, FK9 4LA, Scotland, UK

\author{
*Corresponding author: \\ Lynne Falconer* \\ Institute of Aquaculture \\ University of Stirling \\ Stirling \\ FK9 4LA \\ Scotland \\ UK \\ Email: lynne.falconer1@stir.ac.uk
}

Trevor C. Telfer

Email: t.c.telfer@stir.ac.uk

Lindsay G. Ross

Email: l.g.ross@stir.ac.uk

Accepted refereed manuscript of: Falconer L, Telfer T \& Ross L (2018) Modelling seasonal nutrient inputs from non-point sources across large catchments of importance to aquaculture, Aquaculture, 495, pp. 682-692. DOI: https://doi.org/10.1016/j.aquaculture.2018.06.054

(C) 2018, Elsevier. Licensed under the Creative Commons Attribution-NonCommercial-

NoDerivatives 4.0 International http://creativecommons.org/licenses/by-nc-nd/4.0/ 


\title{
Modelling seasonal nutrient inputs from non-point sources across large catchments of importance to aquaculture
}

\begin{abstract}
Accumulation of nutrients in aquatic systems can have negative impacts on water quality, which can then affect the performance and impact of an aquaculture system. Non-point sources (NPS) and runoff from different land use practices are a major contributor of nutrients to the aquatic environment. However, NPS loading is difficult to identify, and monitoring schemes are often insufficient, particularly across large areas. Aquaculture production areas often extend across large catchments, basins and deltas and knowledge of where there could potentially be higher nutrient loads in the environment would be advantageous to inform strategic site selection and management decisions. This study developed seasonal models within a Geographic Information system (GIS) that can be applied to large catchments of importance to aquaculture to identify areas at risk of nutrient loading from NPS which should be prioritized by monitoring schemes. The models were applied to case study areas in Bangladesh, China, Thailand and Vietnam. The results of the individual models reveal changes in the spatial distribution of priority areas depending on the nutrient (nitrogen or phosphorus) and season. The modelling approach presented here has the advantage that it can be applied to large areas without the need for complex data sets. The model and outputs can also be used to assess impacts of land use and land use change on aquaculture, determine site suitability, establish zones, inform carrying capacity studies and identify potential production and disease risks.
\end{abstract}

Key words: Aquaculture, environment, Geographic Information Systems, monitoring, nonpoint source, nutrients 


\section{Introduction}

Water quality is of fundamental importance to aquaculture, determining the survival, growth and reproduction of species (Boyd and Tucker, 1998; Beveridge, 2004), and it can also affect carrying capacity as well as environmental impact from a system (Boyd and Tucker, 1998; Páez-Osuna, 2001; Beveridge, 2004). It is thus important for the aquaculture sector to identify potential issues that may affect water quality as this could influence planning and management decisions. One such issue is the accumulation of nutrients in an aquatic system as this can lead to a deterioration of water quality (Le et al., 2010; Withers et al., 2014). Nutrients enter the environment in a variety of ways, but one of the main pathways is from nonpoint sources (NPS), which are diffuse sources associated with land management practices, often spread across large areas from which nutrients and pollutants are transported over land by runoff (Carpenter et al., 1998; Wolfe, 2001; Shen et al., 2014). Varied and complex terrain makes it difficult to monitor, measure and manage inputs to the aquatic environment from NPS so many issues are only known about after they have occurred, which may be too late to manage or mitigate for any negative impacts on aquaculture systems.

Identification of areas at risk of nutrient loading from NPS would be useful for aquaculture as this may determine the type of system and species that could be farmed. Different species have different water quality requirements, which may also vary with life stage (Boyd and Tucker, 1998). Some species can tolerate nutrient rich waters, while others cannot and thus potential inputs from NPS, leading to increased nutrient levels, may influence growth, health, production and survival of the farmed stock (Tseng and Chen, 2004; Carbajal-Hernández et al., 2013; Ahmed et al., 2018). There may also be substances and pollutants entering the aquatic system via NPS which could affect the health and welfare of a farmed species and the environment (e.g. pesticides (Schäfer et al., 2011)). By contrast, nutrients entering the environment via NPS may provide an opportunity for aquaculture as they could be a food source for extractive organisms such as shellfish and plants, or where aquaculture is used as 
a bioremediation method (Kim et al., 2015). As aquaculture wastes can also contribute to nutrient loading, it is important to identify areas at risk from NPS loads as there could be cumulative impacts from the combination of multiple sources.

Region-wide planning which considers the entire production area, or potential production area, is important for the ecosystem approach to aquaculture (EAA) (Soto et al., 2008; Ross et al., 2013; Brugère et al., 2018). But, this may present a challenge where key aquaculture production areas extend throughout large catchments such as the Mekong Delta (Falconer et al., 2016). NPS loading is an issue that should be considered at both local and larger catchment or regional scale. At the farm scale, site specific analysis can take place but at a regional scale, monitoring programmes with appropriate temporal and spatial coverage are required to provide information on where, when and how nutrients (and other substances or pollutants) will enter the environment from non-point sources. This will become increasingly important as the aquaculture sector continues to expand, increasing and intensifying production to meet the growing demand for aquatic products (FAO, 2016).

Unlike point-sources which are single, identifiable sources such as outfalls and thus relatively easy to manage, control of NPS and associated substances and pollutants focuses on land management practices across the catchment (Carpenter et al., 1998). The success of any prevention programme will be determined by the ability to target priority areas whilst making effective use of limited time and funds (Moltz et al., 2011). However, regulators and decision makers often have insufficient information on the distribution of NPS as many monitoring systems are primarily designed for point sources (Callan and Thomas, 2010). Models can be used simulate NPS loading, which can then inform monitoring programmes. There are many models available for assessing NPS and associated pollutants (Merrit et al., 2003; Ongley et al., 2010; Xiang et al., 2017). However, as noted by Munafò et al. (2005), NPS models, particularly statistical or physical models, can be complex and require large amounts of data. Therefore, it is difficult or even impossible to apply such models to many study areas, particularly large catchments. 
Spatial models can be used to simulate complex environmental processes and predict the potential scenarios that could occur within a geographical context (Mulligan and Wainwright, 2004). Such models can be used to identify areas at risk of NPS loading and to prioritise areas for monitoring across multiple scales. Recently, there have been efforts to develop simplified spatial models. Munafò et al. (2005) developed a method (Potential non-point pollution index - PNPI tool) to assess river pollution from NPS using widely available data. A similar approach was used by Zhang and Huang (2011) to develop a model using a multi-criteria analysis approach for a large river basin in China. Moltz et al. (2011) also used GIS to develop a NPS pollution risk assessment for the Rio Grande Basin, USA. These models aim to simplify a complex issue providing decision makers with a more efficient method of identifying specific areas which require further attention or analysis.

NPS loading is a seasonal issue (Carpenter et al., 1998), however, few large-scale studies have incorporated this seasonality into their structure. Aquaculture planning requires a seasonal approach as it is not a constant process and there are temporal scales associated with all stages of production from reproduction to harvest. This study builds upon previous work (Munafò et al., 2005; Moltz et al., 2011; Zhang and Huang, 2011) to produce seasonal NPS models for both nitrogen and phosphorus. The overall aim was to develop GIS-based models which could be applied to large catchments of importance to aquaculture, providing guidance to assist key stakeholders and decision makers in establishing effective monitoring schemes which support aquaculture planning and management taking NPS into account.

\section{Methodology}

\subsection{Study areas}

One of the aims of this study was to develop a modelling approach which could be applied in different countries. To achieve this, study areas in four different countries were used; Bangladesh, China, Thailand and Vietnam (Fig. 1A). Each country is a major contributor to World aquaculture production and farms are spread across large areas. In 2014, China, 
Vietnam, Bangladesh and Thailand were the first, fourth, sixth and thirteenth top aquaculture producers in the World, with total aquaculture production of approximately $58,800,000$, $3,410,000,1,960,000$ and 935,000 tonnes respectively (FAO, 2016). Study areas were selected following scoping visits to each of the countries in addition to information from a farmer survey (Little et al., 2009).

Catchments or sub-catchments were used to establish geographical boundaries for the study areas in each country. Fig 1B,C,D,E shows the approximate locations of the surveyed farms providing some context of the aquaculture sector and illustrating the need to monitor inputs from NPS across large catchments. The smallest study area was in Bangladesh, covering approximately $10,000 \mathrm{~km}^{2}$ in the South West of the country; an important area for prawn (Macrobrachium rosenbergii) and shrimp (Litopenaeus vannamei, Penaeus monodon) culture (Fig. 1B). In South East China, a major production area for tilapia (Oreochromis niloticus) and shrimp (L. vannamei, P. monodon), the study area extended across approximately $26,000 \mathrm{~km}^{2}$ (Fig. 1C). In Central Thailand an area of approximately $48,000 \mathrm{~km}^{2}$ included important production areas for tilapia (O. niloticus) and shrimp (L. vannamei, P. monodon) (Fig. 1D). The largest study area was located in the Mekong Delta in Vietnam, a major production area for pangasius (Pangasianodon hypophthalmus) and shrimp (L. vannamei, P. monodon) (Fig. 1E). Due to the natural characteristics of the catchment, the Vietnamese study area covered an area of approximately $66,000 \mathrm{~km}^{2}$ and extended into Cambodia.

The average length and timing of the seasons varies among the four study areas. Consequently, in this study the terms dry season and rainy season refer to slightly different time periods in each country; in Bangladesh the rainy season lasts from June to October with a dry season from November to May (Faruque and Ali, 2005), in Guangdong, South East China, and in Central Thailand, the rainy season is usually from May to October with the dry season from November to April (Seto et al., 2004; Szuster, 2006), and in Vietnam the rainy season is from May to November and the dry season is from December to April (Sakamoto et al., 2009). 


\subsection{Model structure and development}

Models were developed within IDRISI Selva [Clarks Labs, MA, USA] for each study area, with a 30m spatial resolution and georeferenced in the UTM system. NPS loading is a function of climatic factors and site-specific characteristics, including soil type, land management and topography (Wolfe, 2001). These factors are represented in the models through five indices; nutrient generation, runoff, transport, rainfall and population which are combined to produce the final model outputs (Fig. 2). The models use publicly available datasets and data sources that are available for almost anywhere in the world, allowing application in other locations.

\subsubsection{Nutrient generation submodel and index}

The nutrient generation index represents the amount of nitrogen or phosphorus that would be generated by different land use types. Nutrient loading into the environment can be predicted using export coefficients which represent the rate at which a nutrient is exported from a particular land use type to the wider environment (Hanrahan, 2009). Export coefficients from a Chinese study by Ma et al. (2011) were considered most representative of the study areas.

Seasonal land use maps were developed by classifying Landsat 7 ETM + satellite imagery using the remote sensing tools incorporated in IDRISI (Figure 3) and validated using ground truth information (Falconer, 2013). Export coefficients were then assigned to each land use category (Table 1) and converted to $\mathrm{kg} / \mathrm{pixel} / \mathrm{season}$, where each pixel represents an area of $900 \mathrm{~m}^{2}$ (spatial resolution is $30 \mathrm{~m}$ ). Some of the land use categories within the land use maps are quite broad and may contain several different types of land use. For example, a lot of the land classed as trees/heavy vegetation also contains orchards or tree crops, particularly in areas located near aquaculture systems, therefore this category was assigned an export coefficient for orchards (Ma et al., 2011). Orchards have much higher export rates for 
phosphorus than would be expected from wooded areas and consequently there may be some overestimation of risk of phosphorus NPS for areas classed as trees/heavy vegetation which are not orchards.

Atmospheric deposition through rainfall is also a source of pollutants (Ma et al., 2011). The nitrogen and phosphorus content of rainfall for every pixel in the study area was calculated using values of $165 \times 10^{-8} \mathrm{t} / \mathrm{m}^{3} / \mathrm{yr}$ for nitrogen and $5 \times 10^{-8} \mathrm{t} / \mathrm{m}^{3} / \mathrm{yr}$ for phosphorus obtained from Ma et al. (2011). The volume $\left(\mathrm{m}^{3}\right)$ of each pixel was calculated using the length and width of the cell multiplied by the height of rainfall enabling a value ( $\mathrm{kg} /$ pixel/season) to be determined. Generally, bare ground will generate little or no nutrients, therefore no export coefficient was applied to this category and pixels of this type were only assigned the nutrient content of rainfall. Studies have shown that mangroves are often net consumers of both nitrogen and phosphorus and can be considered as nutrient sinks (Alongi, 1996; Rivera-Monroy et al., 1999; Wösten et al., 2003). To avoid overestimation of nutrient extraction by mangroves, the precautionary principle was applied and thus for this study mangroves were assigned a value of zero representing no nutrient generation.

\subsubsection{Runoff submodel and index}

The runoff index uses the soil permeability, land use and slope to account for the potential for runoff. The efficiency of runoff generation is calculated based on the curve number soil retention parameter and follows the methodology in Zhang and Huang (2011). The soil retention parameter characterises the catchment's potential for abstracting and retaining moisture, and thus, the direct runoff potential (Ponce and Hawkins, 1996). The curve number method is a popular technique as it is simple to use and is often the only way to make approximate estimates of overland flow for ungauged watersheds (Yoo \& Boyd, 1994). This technique has been used in many NPS models and is particularly useful for modelling large catchments as shown by Hong et al., (2007) who used the curve number method to simulate 
runoff from major river basins around the world. Curve numbers represent the runoff potential and soil permeability; a lower curve number indicates low runoff potential, whereas a larger number indicates higher runoff potential. Curve numbers $\left(\mathrm{CN}_{2}\right)$ for moderate soil moisture (AMCII) presented in Table 2 were obtained from USDA SCS (1986) and Shi et al. (2007).

GIS layers representing the four hydrological soil groups were reclassified from the seven drainage classes used in the Harmonized World Soil Database (HWSD) (FAO/IIASA/ISRIC/ISS-CAS/JRC, 2012). The values of $\mathrm{CN}_{2}$ in Table 2 are only suitable for a $5 \%$ slope and therefore must be adjusted $\left(\mathrm{CN}_{2 s}\right)$ to take into account the different slopes $(\theta)$ as described by Zhang and Huang (2011). A layer representing \% slope was produced from the SRTM DEM (Shuttle Radar Topography Mission Digital Elevation Model) (NASA, 2009). In order to calculate $\mathrm{CN}_{2 s}$, Equation 1 was first used to determine $\mathrm{CN}_{3}$ which is the curve number for high moisture condition (AMCIII). Equation 2 was then used to calculate $\mathrm{CN}_{2 \mathrm{~s}}$ and finally this value was used in Equation 3 to calculate $S$ which is the retention parameter. A lower retention parameter results in higher potential for runoff (Soltani and Sinclair, 2012).

$$
\begin{array}{ll}
C N_{3}=C N_{2} \exp \left[0.00673\left(100-C N_{2}\right)\right] & \text { [Equation 1] } \\
C N_{2 s}=\frac{\left(C N_{3}-C N_{2}\right)}{3}[1-2 \exp (-13.86 \theta)]+C N_{2} & \text { [Equation 2] } \\
S=25.4\left(\frac{1000}{C N_{2 s}}-10\right) & \text { [Equation 3] }
\end{array}
$$

\subsubsection{Transport submodel and index}

The transport index represents the potential movement of surface runoff and the subsequent potential for NPS loading. The movement of surface water on land, and ensuing soil erosion, is dependent on both the length and inclination of the slope (Wischmeier and Smith 1978; Brooks et al., 2013). Slope length and slope steepness are the two components of the LS 
factor, also known as the topographic factor, which is part of the Universal Soil Loss Equation (USLE) which has been widely used throughout the world to predict and estimate soil loss (Blanco and Lal, 2008). The LS factor is used within the USLE to represent the expected ratio of soil loss from the area of interest to the standard USLE plot (Wischmeier and Smith 1978; Blanco and Lal, 2008). Slope length represents overland flow from the point of origin to where deposition begins or the runoff reaches a defined channel (Brooks et al., 2013). Therefore as increasing values of LS indicate steeper and/or longer slopes it can represent the potential for runoff and the associated erosion which leads to NPS loading.

The methodology of Lufafa et al. (2003) was used in this study, where the LS factor was calculated using two equations depending on the steepness of the slopes. Equation 4 was used for slopes with a steepness below 21\% (Wischmeier and Smith, 1978) and Equation 5 was used for slopes with a steepness above 21\% (Gaudasamita, 1987, in Lufafa et al., 2003).

$$
\begin{array}{ll}
L S(\text { slopes }<21 \%)=\left(\frac{\lambda}{22.1}\right)^{m}\left(65.41 \sin ^{2} Y+4.56 \sin Y+0.065\right) & \text { [Equation 4] } \\
L S(\text { slopes }>21 \%)=\left(\frac{\lambda}{22.1}\right)^{0.7}\left(6.432 \sin \left(Y^{0.79}\right) \times \cos (Y)\right) & \text { [Equation 5] }
\end{array}
$$

Where:

$$
\begin{aligned}
& \lambda \text { is slope length }(\mathrm{m}) \\
& Y=\text { slope (radians) } \\
& \mathrm{m}=0.5 \text { if slope } \geq 5 \% \\
& 0.4 \text { if slope between } 3-5 \% \\
& 0.3 \text { if slope between } 1-3 \%, \\
& 0.2 \text { if slope }<1 \%
\end{aligned}
$$

Slope and aspect were calculated from the SRTM DEM (NASA, 2009) following pit removal. These pits (also known as sinks or depressions) are cells or pixels where the surrounding cells or pixels are all at a higher elevation, which often results in problems for hydrological modelling 
as they disrupt the natural flowlines and drainage topography (Huggett and Cheesman, 2002; Reuter et al., 2009). Some depressions may be naturally occurring, resulting in endorheic lakes; however, often they result from errors in the interpolation, incorrect data, insufficient information or problems with the pixel resolution during DEM production (Huggett and Cheesman, 2002). Therefore it was decided to remove the depressions through pit removal prior to further analysis.

The aspect layer was used to identify the direction of flow. This layer was then reclassified, using a method described by Pérez (2002), so that values between $0-22.5^{\circ}, 67.5-112.5^{\circ}$, $157.5-202.5^{\circ}, 247.5-292.5^{\circ}$ and $337.5-360^{\circ}$ were given the value of the length of one side of a pixel and values between $22.5-67.5^{\circ}, 112.5-157.5^{\circ}, 202.5-247.5^{\circ}$ and $292.5-337.5^{\circ}$ were given the value of the diagonal distance of the pixel. The resulting reclassified layer represents flow direction length and was used to calculate slope length $(\lambda)$ in Equation 6 , which was used in Equation 4 and 5 to calculate the LS factor.

Slope length $(\lambda)=\frac{\text { Flow direction length }}{\cos \theta}$

[Equation 6]

Where: $\theta$ is the slope angle.

\subsubsection{Rainfall index}

The rainfall index represents the potential for rainfall to drive runoff and subsequent NPS loading. Rainfall can detach soil particles and initiate the transport of the detached particles, substances and pollutants in runoff (Blanco and Lal, 2008); therefore, higher levels of rainfall will result in increased runoff. The seasonal distribution of rainfall across each of the study areas was sourced from the WorldClim dataset (Hijmans et al., 2005). 


\subsubsection{Population index}

The population index used data obtained from the LandScan 2008 database (Oak Ridge National Laboratory, 2008) and represents population pressure on the environment and the subsequent potential for nutrient input into the environment. In Asia, water resources such as the rivers, lakes and coastal areas are important not only as sources of food but also for irrigation, transport, waste disposal and washing (McGregor, 2008). Therefore, as areas with higher population are likely to result in higher loading of nutrients into the environment it is important to account for the potential population pressure and include this index within the overall model.

\subsubsection{Normalisation and final model development}

As the individual attributes were measured on different numerical scales the data had to be normalized to obtain a comparable monotonic linear scale ranging between 0 and 1 (Voogd, 1983; Witten et al., 2011). Across large areas such as those included in this study there can be a great variation in variables, therefore a log transformation was performed on each index to account for such variation and reduce the influence of extreme outliers prior to normalisation and overall inclusion in the model. Equation 7 (Voogd, 1983) shows the calculation involved in the normalization process; where $\mathrm{R}_{\mathrm{i}}$ is the raw score. Weightings were applied to each index after normalization and before combination in the final model development (Equation 8). These weightings were based on discussions with an expert group comprising three hydrologists and three environmental scientists, in addition to literature reviews and the consultation of previous studies by Munafo et al. (2005) and Zhang and Huang (2011).

standardized score $=\frac{R_{\mathrm{i}}-\min R_{\mathrm{i}}}{\max R_{\mathrm{i}}-\min R_{i}}$

[Equation 7] 
where: $\mathrm{N}=$ Nutrient generation index

$$
\begin{aligned}
& T=\text { Transport index } \\
& R u=\text { Runoff index } \\
& R a=\text { Rainfall index } \\
& P=\text { Population index }
\end{aligned}
$$

The final model output has a continuous scale of 0 to 10 which was reclassified using equal intervals for easier interpretation by decision makers. Scores from 0.001 to 2 were considered very low priority areas for monitoring as they have the lowest risk of NPS loading, scores from 2 to 4 were considered low priority areas for monitoring, scores from 4 to 6 were considered moderate priority areas for monitoring, scores from 6 to 8 were considered high priority areas for monitoring and scores from 8 to 10 were considered very high priority areas for monitoring as they have the highest risk of NPS loading. Scores below 0.001 were reclassified to 0 as they are not considered to be areas at any risk of NPS loading.

\section{Results}

The model outputs for Bangladesh, China, Thailand and Vietnam are shown in Figs 4, 5, 6 and 7 respectively. Table 3 summarises the area $\left(\mathrm{km}^{2}\right.$ and \% of total area) covered by each NPS category. There were no areas with a score of 0 , therefore each pixel had a very low, low, moderate, high or very high priority for monitoring.

In Bangladesh rainfall is the main driver of the seasonal differences in the models (Fig. 4), consequently the overall seasonal spatial pattern for both nutrients is similar. Approximately $20 \%$ of the study area is considered high priority for monitoring nitrogen NPS in the dry season, and many prawn farms are located in these areas (Figs. $4 \mathrm{~A}, 4 \mathrm{~B}$ ), while $25 \%$ is considered 
high priority for phosphorus NPS (Fig 4F). In the rainy season, approximately $10 \%$ of the study area is considered to be high priority for monitoring of both nitrogen and phosphorus NPS, most of which occurs in the south east of the study area.

In the Chinese study area some of the highest priority areas for monitoring across all models are found inland, including areas which are important for tilapia production (Figs. 5A, 5C, 5E and $5 G$ ). This suggests extra year-round monitoring points may be needed in this area. Not all farms are located in areas with the same level of priority throughout the year as shown by Figs. 5B, 5D, 5F and 5H. However, as the models have been normalized individually, this does not necessarily mean the level of risk changes for that specific location; it could also mean there are other areas which have higher/lower risk of NPS, and thus the priority for monitoring changes on that basis as those areas may need more/less attention.

In Thailand most of the high priority areas are located in the east of the study area, particularly in the south east (Figs. $6 \mathrm{~B}, 6 \mathrm{D}, 6 \mathrm{~F}$ and $6 \mathrm{H}$ ), which is an important shrimp production area. This is mainly due to the distribution of rainfall, one of the key drivers of NPS loading. Across all models, the dominant category is moderate priority, which covers at least $50 \%$ of the study area in the phosphorus models and over $60 \%$ for the nitrogen models (Table 3 ). However, even in areas dominated by low and moderate priority, there are small areas of high priority (Figs. 6A 6C, 6E and 6G).

The results from the Vietnamese models are shown in Fig. 7. In the dry season in Vietnam some of the areas with the highest priority for both nitrogen and phosphorus NPS are inland where there are many pangasius farms (Figs. 7A and 7E), whilst nearer the mouth of the Mekong, areas have low and moderate priority (7B and 7F). In the rainy season water covers almost $40 \%$ of the study area; this includes rivers, flooded land and rice fields. High priority areas for both nitrogen and phosphorus are found in the north and south of the study area, the latter is a popular area for shrimp farming (Fig. 7C, 7G). As with all of the other study areas 
(for all seasons and nutrients), the areas with the lowest risk of NPS are the areas covered by mangroves (Figs. 7D, 7H) which are generally considered to be nutrient sinks.

\section{Discussion}

The approach in this study used a combination of five indices to develop models which can be used to prioritise areas for monitoring NPS loading in four areas of importance to global aquaculture production (Fig. 1). The results of the individual models (Figs. 4, 5, 6 and 7) show that the spatial distribution of priority areas changes depending on the nutrient and season. This corresponds with results from other studies (Van Chinh, 2013; Shen et al., 2014), where model outputs also indicated there were changes in the spatial distribution of NPS loading.

The spatial models presented in this study do not aim to quantify the amount of nitrogen or phosphorus entering the environment; rather, they estimate the relative risk across large areas based on key factors (indices) which generally contribute to NPS loading. As the models are index based, they only show which areas are more at risk (higher priority) than others and do not have a quantitative baseline level; consequently, an area that has the lowest priority could still have high levels of nitrogen and phosphorus NPS. The models have not been designed to replace more complex and site-specific studies; their intended use is across large catchments to improve monitoring schemes and stakeholder knowledge by providing information on areas at risk of NPS loading. This follows the recommendation of Moltz et al. (2011) who note that large catchments are difficult to model using data-intensive, highly complicated, process-based models. Instead, a coarser level of data and modelling processes can be employed to provide an initial identification of select areas within the larger region which would be at risk from high nutrient loading and therefore require further attention.

The seasonal approach, which considers land use changes, is particularly important for aquaculture as regulators can prioritise areas for monitoring in particular seasons where aquatic systems or species are more vulnerable to nutrient loading. Furthermore, whilst the 
modelling approach has been designed to guide and enhance monitoring programmes for NPS loading, it could also be used to consider the impact of surrounding land use, land use change and climate change on aquaculture and the implications this could have for production and disease. Nutrient inputs from the surrounding area could impact the overall site suitability and carrying capacity of the system, therefore the models could also be used as part of site selection or zoning (Ross et al., 2013). Combining the NPS model outputs with site selection models or other modelling approaches (e.g. Ferreira et al., 2015; Falconer et al., 2016) could provide additional decision support for the industry and more holistic and objective planning.

Assessing NPS loading across large catchments rather than solely at a local scale allows identification of potential issues which may otherwise be unknown. This also aligns with the suggestions by Patterson et al. (2013) that since NPS is a multi-scalar issue there is a need to consider multiple spatial scales within management plans. During the Vietnamese dry season, inland areas of the Mekong river are at a higher risk of both nitrogen (Fig. 7A) and phosphorus (Fig. 7E) NPS loading than downstream areas (Figs. 7B, 7F). Local level analysis may show that downstream areas are lower risk; however, wider scale analysis shows there are higher risk areas upstream which may impact downstream water quality as nutrients are flushed downstream.

As with any modelling process it is essential to acknowledge the limitations of models, which are not alternatives to observations, but, powerful tools in providing further understanding and developing and testing theory (Mulligan and Wainwright, 2004). The models have been designed so they can be applied to any study area using readily available data (whether that is country specific or global datasets). Although they will not be as sensitive as site specific models, this allows application in areas which may not have the resources to collect data or perform more intensive analysis.

\section{Conclusions}


The modelling approach developed in this study is designed to show the level of risk from NPS within a catchment; enabling effective monitoring programs and/or mitigation procedures to be established. It is a simplified model based on publicly available datasets which can be applied to large areas without the need for generation of complex field data sets; saving time and money, allowing priority areas to be targeted efficiently. Such an approach is necessary where aquaculture production extends (or has the potential to extend) across large catchments. The model outputs could also be used to assess impact of surrounding land use on aquaculture, determine site suitability and identify potential production and disease risks. The method can be used to support regional development within the EAA and strategic planning for regional and global food security.

\section{Acknowledgements}

This work was funded by the EU-FP7 Sustaining Ethical Aquaculture Trade (SEAT) project (project number 222889) and the Institute of Aquaculture, University of Stirling. The authors would also like to thank the SEAT project partners who carried out the farmer survey in each country.

\section{References}

Ahmed, N., Thompson, S. and Glaser, M. 2018. Transforming organic prawn farming in Bangladesh: Potentials and challenges. Journal of Cleaner Production, 172: 3806-3816.

Alongi, D.M. 1996. The dynamics of benthic nutrient pools and fluxes in tropical mangrove forests. Journal of Marine Research, 54: 123 - 148.

Beveridge, M.C.M. 2004. Cage aquaculture. $3^{\text {rd }}$ edition. Blackwell Publishing, Oxford, UK. 376pp.

Blanco, H. and Lal, R. 2008. Principles of soil conservation and management. Springer, London. 617pp. 
Boyd, C. and Tucker, C.S. 1998. Pond aquaculture water quality management. Springer Science + Business Media, New York, USA. 700pp.

Brooks, K.N., Ffolliott, P.F. and Magner, J.A. 2013. Hydrology and the management of watersheds. Fourth edition. Wiley Blackwell, Oxford, UK. 545pp.

Brugère, C., Aguilar-Manjarrez, J.A., Beveridge, M.C.M and Soto, D. 2018. The ecosystem approach to aquaculture 10 years on - a critical review and consideration of its future role in blue growth. Reviews in Aquaculture. doi: 10.1111/raq.12242

Callan, S.J. and Thomas, J.M. 2010. Environmental economics and management: theory, policy and applications. 5th edition. South-Western Cengage Learning, Ohio, USA. 545pp.

Carbajal-Hernández, J.J., Sánchez-Fernández, L.P., Villa-Vargas, L.A., Carrasco-Ochoa, J.A. and Marinínez-Trinidad, J.F. 2013. Water quality assessment in shrimp culture using an analytical hierarchical process. Ecological Indicators, 29: 148-158.

Carpenter, S.R., Caraco, N.F., Correll, D.L., Howarth, R.W., Sharpley, A.N. and Smith, V.H. 1998. Nonpoint pollution of surface waters with Phosphorus and Nitrogen. Ecological Applications, 8(3): 559-568.

Falconer, L. 2013. Spatial modelling and GIS-based decision support tools to evaluate the suitability of sustainable aquaculture development in large catchments. PhD thesis, University of Stirling, Scotland, UK. 312pp.

Falconer L, Telfer T and Ross $L$.2016. Investigation of a novel approach for aquaculture site selection, Journal of Environmental Management, 181, pp. 791-804.

FAO. 2016. The state of World fisheries and aquaculture 2016. Contributing to food security and nutrition for all. Rome. 200pp.

FAO/IIASA/ISRIC/ISS-CAS/JRC. 2012. Harmonized World Soil Database (version 1.2). FAO, Rome, Italy and IIASA, Laxenburg, Austria.

Faruque, H.S.M. and Ali, M.L., 2005. Climate change and water resources management in Bangladesh. In: Mirza, M.M.Q. and Ahmad, Q.K. eds. Climate change and water resources in South Asia. Taylor \& Francis Group plc, London, UK, pp 231-254.

Ferreira, J.G., Falconer, L., Kittiwanich, J., Ross, L., Saurel, C., Wellman, K., Zhu, C. and Suvanachai, P. 2015. Analysis of production and environmental effects of Nile tilapia and white shrimp culture in Thailand. Aquaculture, 447: 23-36.

Hanrahan, G. 2009. Modelling of pollutants in complex environmental systems, volume 1. ILM Publications, Hertfordshire, 376pp.

Hijmans, R.J., S.E. Cameron, J.L. Parra, P.G. Jones and A. Jarvis, 2005. Very high resolution interpolated climate surfaces for global land areas. International Journal of Climatology, 25: 1965-1978.

Hong, Y., Adler, R.F., Hossain, F., Curtis, S. and Huffman, G.J. 2007. A first approach to global runoff simulation using satellite rainfall estimation. Water Resources Research, 43(2):285-294. 
Huggett, R. and Cheesman, J. 2002. Topography and the environment. Pearson Education Limited, Essex, UK. 292pp.

Kim, J.K., Kraemer, G.P. and Yarish, C. 2015. Use of sugar kelp aquaculture in Long Island Sound and the Bronx River Estuary for nutrient extraction. Marine Ecology Progress Series, 531: 155-166.

Le, C., Zha, Y., Li, Y., Sun, D., Lu, H. and Yin, B. 2010. Eutrophication of lake waters in China: cost, causes and control. Environmental Management, 45(4): 662-668.

Little DC, Murray F, Telfer T, Young J, Ross L, Hill B, Dalsgaard A, van den Brink PJ, Guinee J, Kleijn R, Mungkung R, Yi Y, Min J, Liping L and Huanan L (2009) Sustaining ethical trade in farmed aquatic products between Asia and the EU. In: Millar K, Hobson West P, Nerlich B (ed.). Ethical Futures: Bioscience and Food Horizons , Wageningen, The Netherlands: Wageningen Academic Publishers, pp. 226-231.

Lufafa, A., Tenywa, M.M., Isabirye, M., Majaliwa, M.L.G. and Woomer, P.L. 2003. Prediction of soil erosion in a Lake Victoria basin catchment using a GIS-based Universal Soil Loss model. Agricultural Systems, 76(3): 883-894.

Ma, X., Li, Y., Zhang, M., Zheng, F. and Du, S. 2011. Assessment and analysis of non-point source nitrogen and phosphorus loads in the three forges reservoir area of Hubei province, China. Science of the Total Environment, 412-413: 154 - 161.

McGregor, A. 2008. Southeast Asian Development. Routledge, Oxon, UK. 251 pp.

Merrit, W.S., Letcher, R.A. and Jakeman, A.J. 2003. A review of erosion and sediment transport models. Environmental Modelling \& Software, 18(8-9): 761-799.

Moltz, H.L., Rast, W., Lopes, V.L. and Ventura, S.J. 2011. Use of spatial surrogates to assess the potential for non-point source pollution in large watersheds. Lakes \& Reservoirs: Research and Management, 6: 3 - 13.

Mulligan, M. and Wainwright, J., 2005. Modelling and model building. In: Wainwright, J. Mulligan, M. eds. Environmental modelling: Finding simplicity in complexity. John Wiley and Sons Ltd, West Sussex, England. 408pp.

Munafò, M., Cecchi, G., Baiocco, F. and Mancini, L. 2005. River pollution from non-point sources: a new simplified method of assessment. Journal of Environmental Management, 77: 93-98.

NASA. 2009. Shuttle Radar Topography Mission: The mission to map the world. [Internet]. NASA, Washington D.C. Available from <http://www2.jpl.nasa.gov/srtm/>

Oak Ridge National Laboratory. 2008. Landscan population database 2008. [Internet] Oak Ridge National Laboratory, Tennessee, USA. Available from :

$<$ http://web.ornl.gov/sci/landscan/>

Ongley, E.D., Xiaolan, Z. and Tao, Y. 2010. Current status of agricultural and rural non-point source pollution assessment in China. Environmental Pollution, 158(5): 1159-1168. 
Páez-Osuna, F. 2001. The environmental impact of shrimp aquaculture: causes, effects, and mitigating alternatives. Environmental Management, 28(1): 131-140.

Patterson, J.J., Smith, C. and Bellamy, J. 2013. Understanding enabling capacities for managing the 'wicked problem' of nonpoint source water pollution in catchments: a conceptual framework. Journal of Environmental Management, 128: 441-452.

Pérez, O. 2002. GIS-based models for optimisation of marine cage aquaculture in Tenerife, Canary Islands. PhD thesis, University of Stirling, UK. 332pp.

Ponce, V.M. and Hawkins, R.H. 1996. Runoff curve number: has it reached maturity? Journal of Hydrologic Engineering, 1 (1): 11 - 19.

Reuter, H.I., Hengl, T., Gessler, P. and Soille, P. 2009. Chapter 4 preparation of DEMs for Geomorphometric analysis. Developments in Soil Science, 33: 87-120.

Rivera-Monroy, V.H., Torres, L.A., Bahamon, N., Newmark, F. and Twilley, R.R. 1999. The potential use of mangrove forests as nitrogen sinks of shrimp aquaculture pond effluents: the role of denitrification. Journal of the World Aquaculture Society, 30(1): 12-25.

Ross, L.G., Telfer, T.C., Falconer, L., Soto, D. \& Aguilar-Manjarrez, J., eds. 2013. Site selection and carrying capacities for inland and coastal aquaculture. FAO/Institute of Aquaculture, University of Stirling, Expert Workshop, 6-8 December 2010. Stirling, the United Kingdom of Great Britain and Northern Ireland. FAO Fisheries and Aquaculture Proceedings No. 21. Rome, FAO. 282 pp.

Sakamoto, T., Phung, C.V., Kotera, A., Nguyen, K.D. and Yokozawa, M. 2009. Analysis of rapid expansion of inland aquaculture and triple rice-cropping areas in a coastal area of the Vietnamese Mekong Delta using MODIS time-series imagery. Landscape and Urban Planning, 921: 34 - 46.

Schäfer, R.B., van den Brink, P.J. and Liess, M. 2011. Impacts of pesticides on freshwater ecosystems. In: Sánchez-Bayo, F., van den Brink, P.J. and Mann, R.M. eds. Ecological Impacts of Toxic Chemicals. Bentham Science Publishers, DOI: 10.2174/97816080512121110101. pp 111-137.

Seto, K.C., Woodcock, C.E. and Kaufmann, R.K. 2004. Changes in land cover and land use in the Pearl river delta, China. In: Gutman, G., Janetos, A.C., Justice, C.O., Moran, E.F., Mustard, J.F., Rindfuss, R.R., Skole, D., Turner, B.L. and Cochrane, M.A. eds. Land Change Science: observing, monitoring and understanding trajectories of change of the Earth's surface. Springer, The Netherlands, pp. 227-242.

Shen, Z., Qiu, J., Hong, Q. and Chen, L. 2014. Simulation of spatial and temporal distributions of non-point source pollution load in the Three Gorges Reservoir Region. Science of The Total Environment, 493: 138-146.

Shi, P.J., Yuan, Y., Zheng, J., Wang, J.A., Ge, Y. and Qiu, G.Y. 2007. The effect of land use/cover change on surface runoff in Shenzen region, China. Catena, 69: 31-35.

Soltani, A. and Sinclair, T.R. 2012. Modeling physiology of crop development, growth and yield. CABI International, Oxford, UK. 322pp. 
Soto, D., Aguilar-Manjarrez, J. and Hishamunda, N. 2008. Building an ecosystem approach to aquaculture. FAO/Universitat de les Illes Balears Expert Workshop. 7 - 11 May 2007, Palma de Mallorca, Spain. FAO Fisheries and Aquaculture Proceedings. No. 14. FAO, Rome. 221pp.

Szuster, B.W. 2006. Review of shrimp farming in central Thailand. In: Leung, P.S. and Engle, C. Eds. Shrimp culture: economics, market and trade. Blackwell Publishing, lowa, USA, 155-166.

Tseng, I.T. and Chen, J.C. 2004. The immune response of white shrimp Litopenaeus vannamei and its susceptibility to Vibrio alginolyticus under nitrite stress. Fish \& Shellfish Immunology, 17: 325-333.

USDA SCS. 1986. Urban hydrology for small watersheds. Technical Release 55. USDA, Washington DC. 164pp.

Van Chinh, L., Iseri, H., Hiramatsu, K., Harada, M. and Mori, M. 2013. Simulation of rainfall runoff and pollutant load for Chikugo River basin in Japan using a GIS-based distributed parameter model. Paddy and Water Environment, 11(1-4): 97-112.

Voogd, H. 1983. Multicriteria evaluation for urban and regional planning. Pion, London. 367pp.

Wischmeier, W.H., and Smith, D.D. 1978. Predicting rainfall erosion losses - a guide to conservation planning. US. Department of Agriculture, Agriculture Handbook No. 537. 67pp.

Withers, P.J.A., Neal, C., Jarvie, H.P. and Doody, D.G. 2014. Agriculture and eutrophication: where do we go from here? Sustainability, 6(9): 5853-5875.

Witten, I.H., Frank, E. and Hall, M.A., 2011. Data mining: practical machine learning tools and techniques. 3rd edition. Elsevier Inc, Massachusetts, USA. 629pp.

Wolfe, M.L. 2001. Hydrology. In: Ritter, W.F. and Shirmohammadi, A. eds. Agricultral nonpoint source pollution: watershed management and hydrology. CRC Press LLC, Florida, USA. pp. 1-29.

Wösten, J.H.M., de Willigen, P., Tri, N.H., Lien, T.V. and Smith, S.V. 2003. Nutrient dynamics in mangrove areas of the Red River Estuary in Vietnam. Estuarine, Coastal and Shelf Science, 57: 65-72.

Xiang, C., Wang, Y. and Liu, H. 2017. A scientometrics review on nonpoint source pollution research. Ecological Engineering, 99: 400-408.

Yoo, K.H. and Boyd, C.E. 1994. Hydrology and water supply for pond aquaculture. Chapman and Hall, New York. 483pp.

Zhang, H. and Huang, G.H. 2011. Assessment of non-point source pollution using a spatial multicriteria analysis approach. Ecological Modelling, 222: 313-321. 

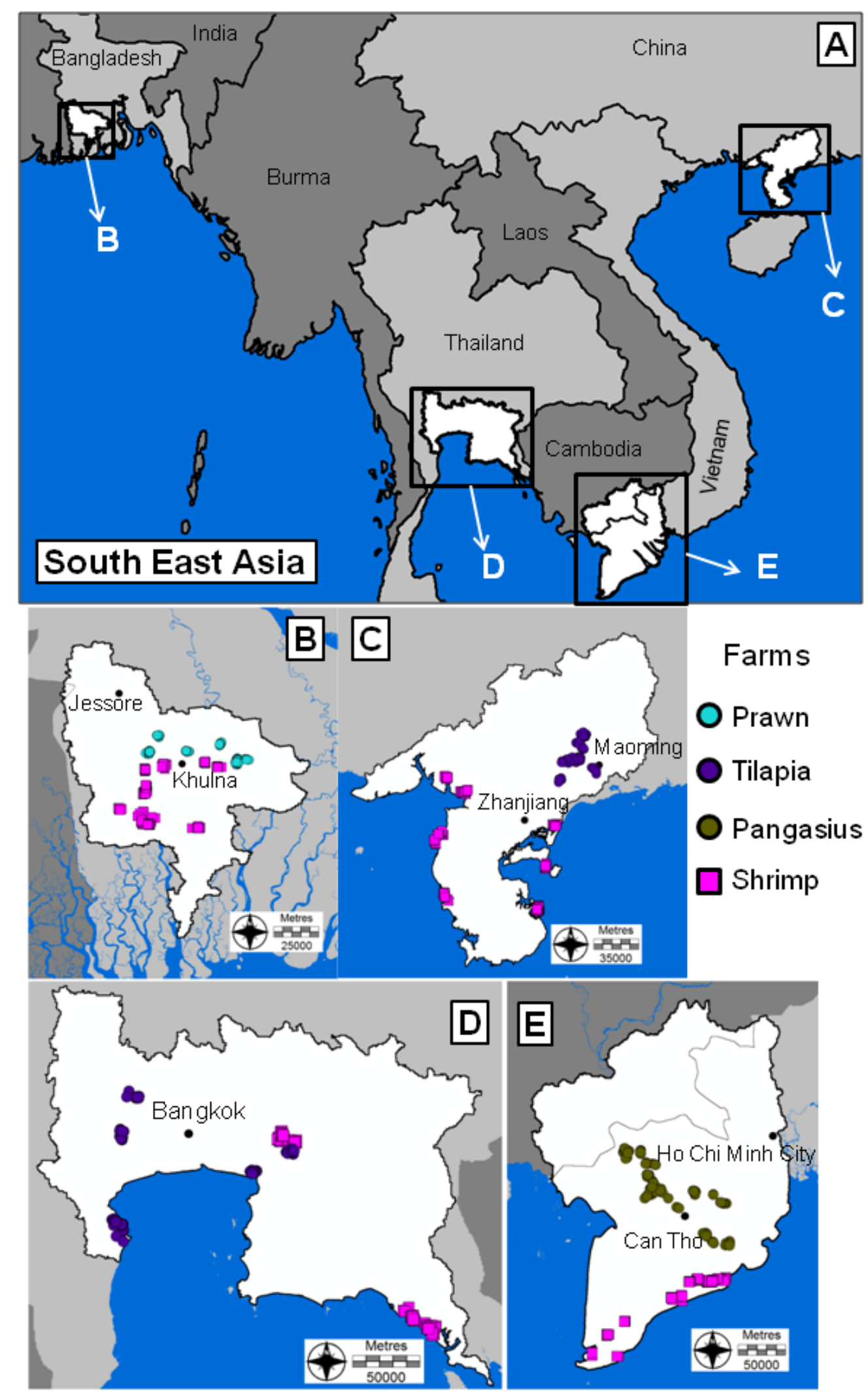

Figure 1: The four study areas in South East Asia (Box A): Bangladesh - includes prawn and shrimp farms (Box B), China - includes tilapia and shrimp farms (Box C), Thailand (Box D) includes tilapia and shrimp farms, and Vietnam - includes pangasius and shrimp farms (Box 


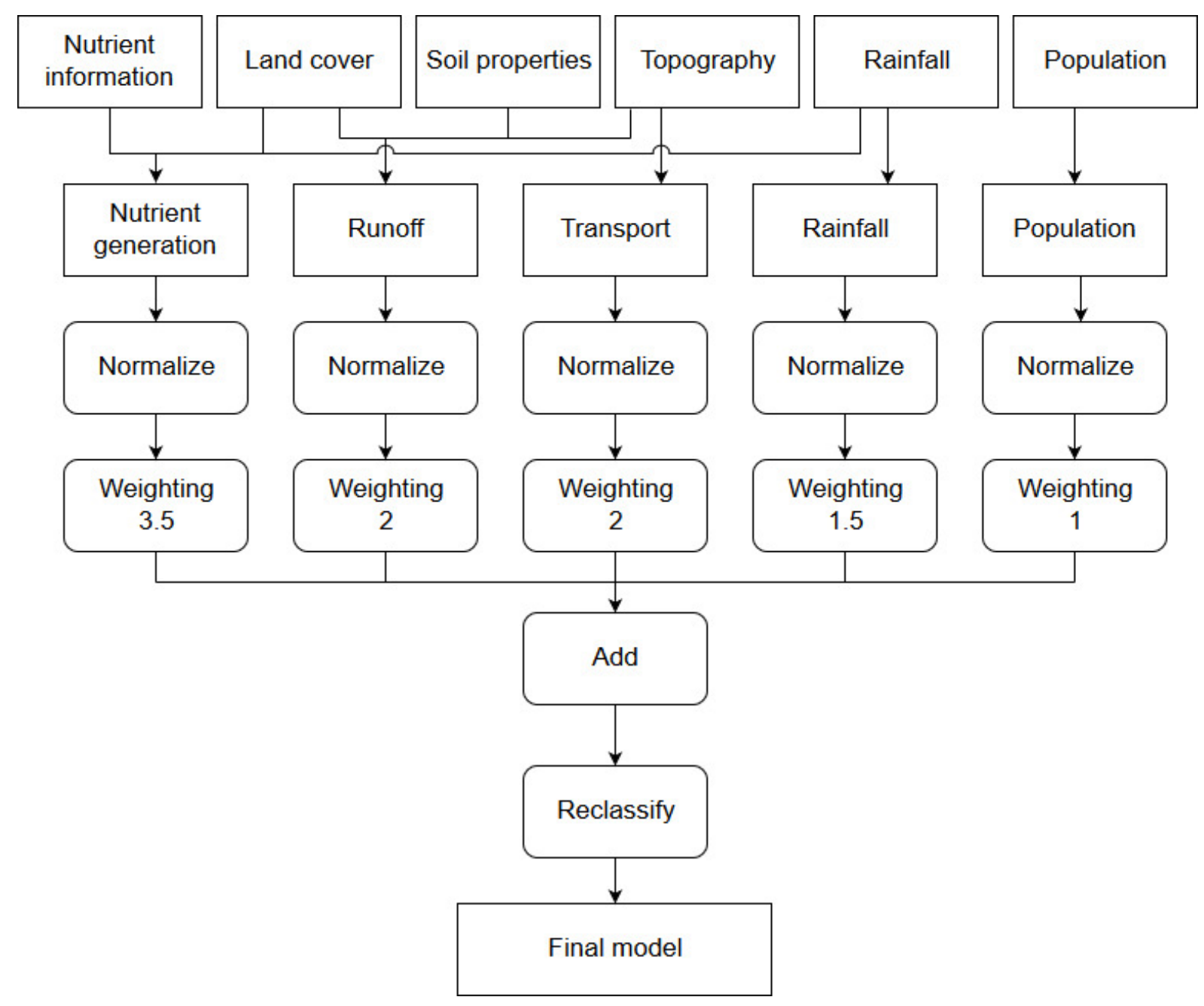

Figure 2: Structure of the NPS loading models. 

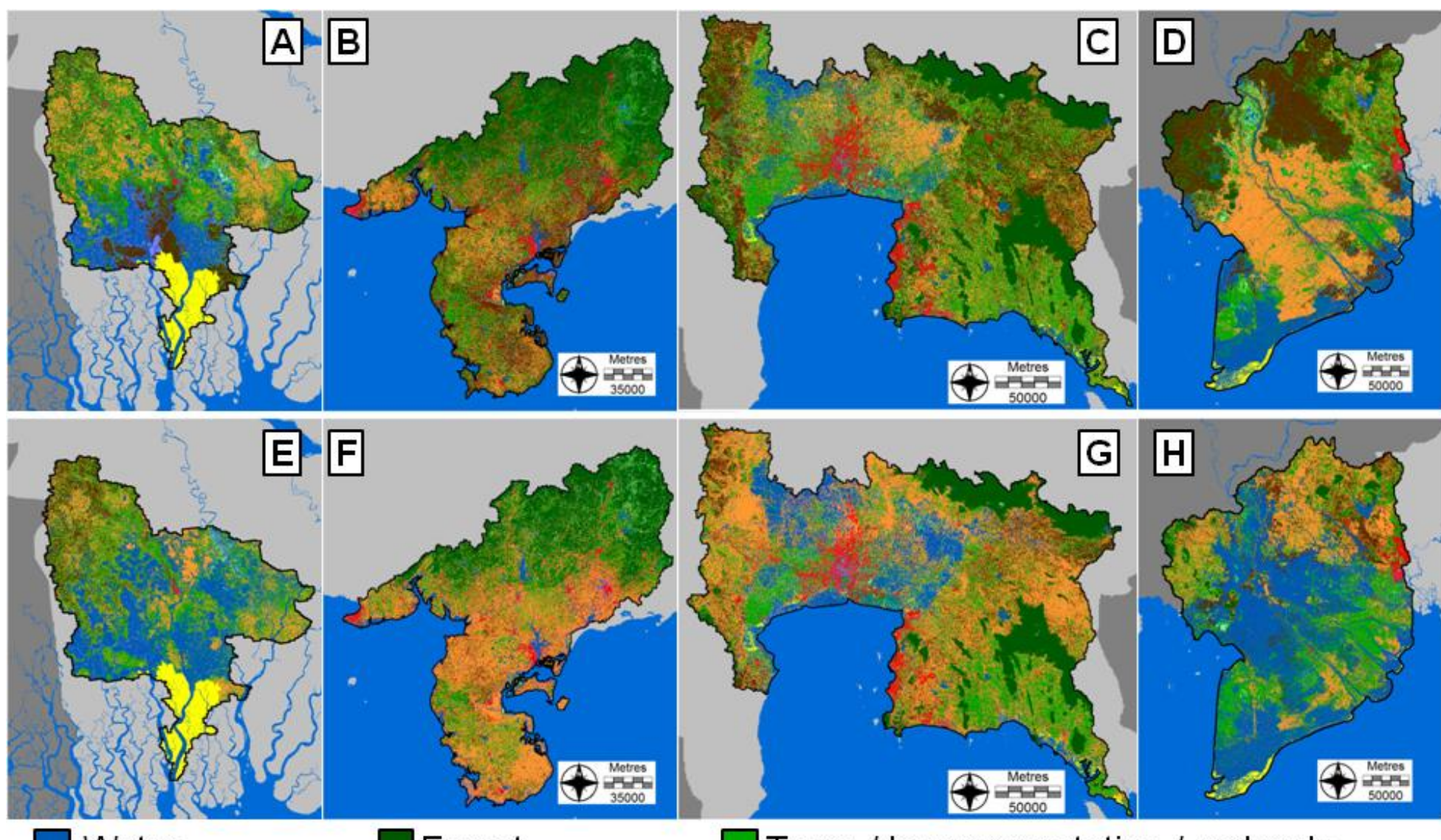

$\square$ Water

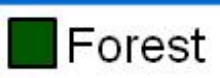

$\square$ Bare ground

$\square$ Mangroves

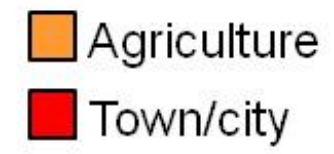

G $\mathrm{H}$ $\square$ Trees / heavy vegetation / orchards

$\square$ Grassland / shrubland

$\square$ Soil/light vegetation

Figure 3: Land use for Bangladesh (A), China (B), Thailand $(C)$ and Vietnam (D) in the dry season and Bangladesh (E), China (F), Thailand (G) and Vietnam $(\mathrm{H})$ in the rainy season. 

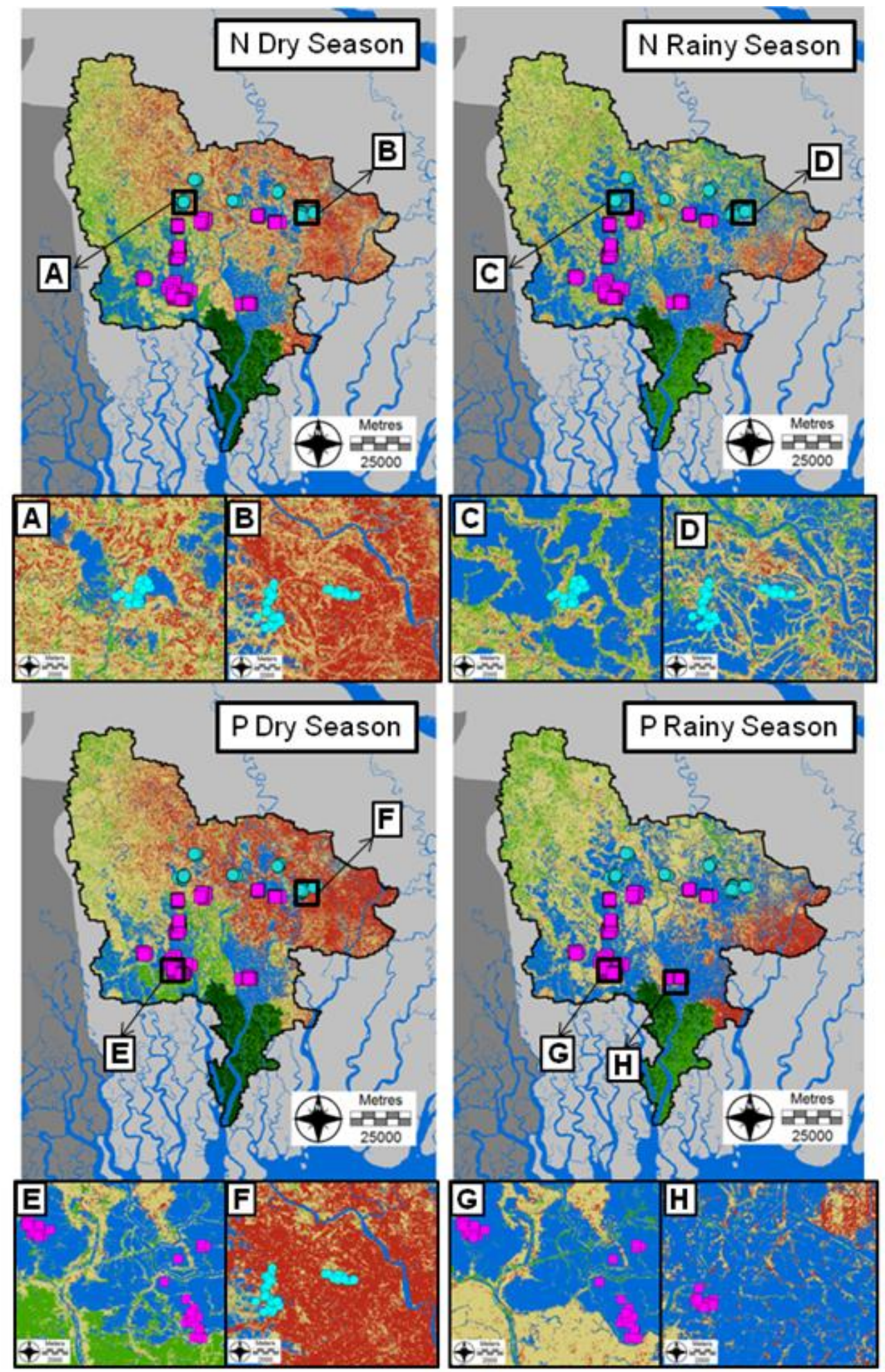

Priority

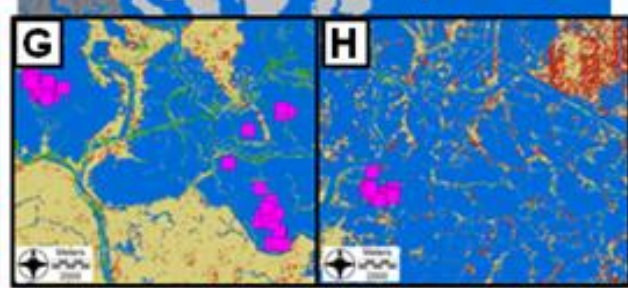

Very low

$\square$ High

$\square$ Low

$\square$ Moderate

$\square$ Very high

O Prawn farms $\square$ Shrimp farms

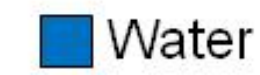

Figure 4: Results from the NPS models for the study area in Bangladesh. The prawn and shrimp farms from the farmer survey are included for reference. The zoomed boxes show areas of interest for further inspection. 


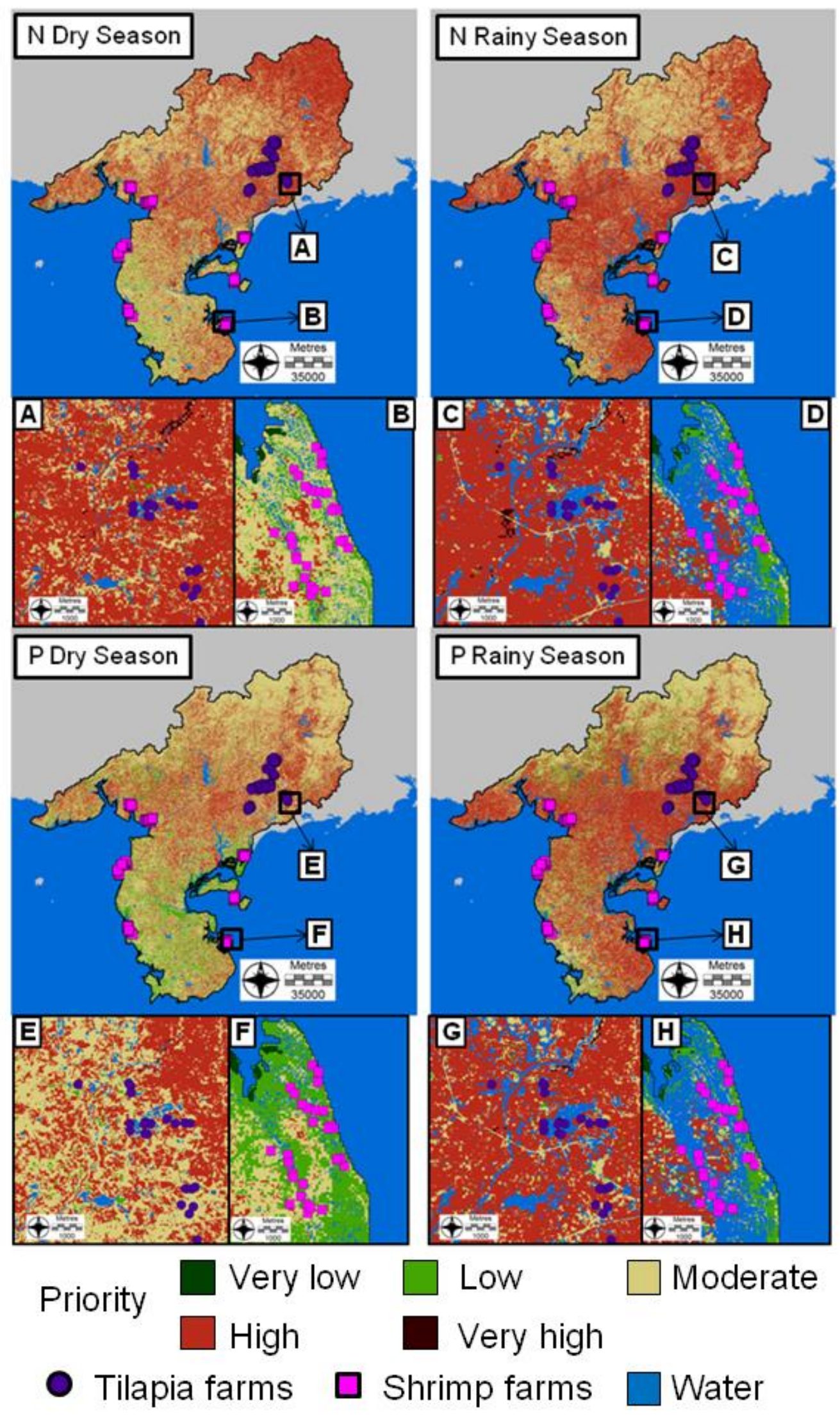

Figure 5: Results from the NPS models for the study area in China. The tilapia and shrimp farms from the farmer survey are included for reference. The zoomed boxes show areas of interest for further inspection. 


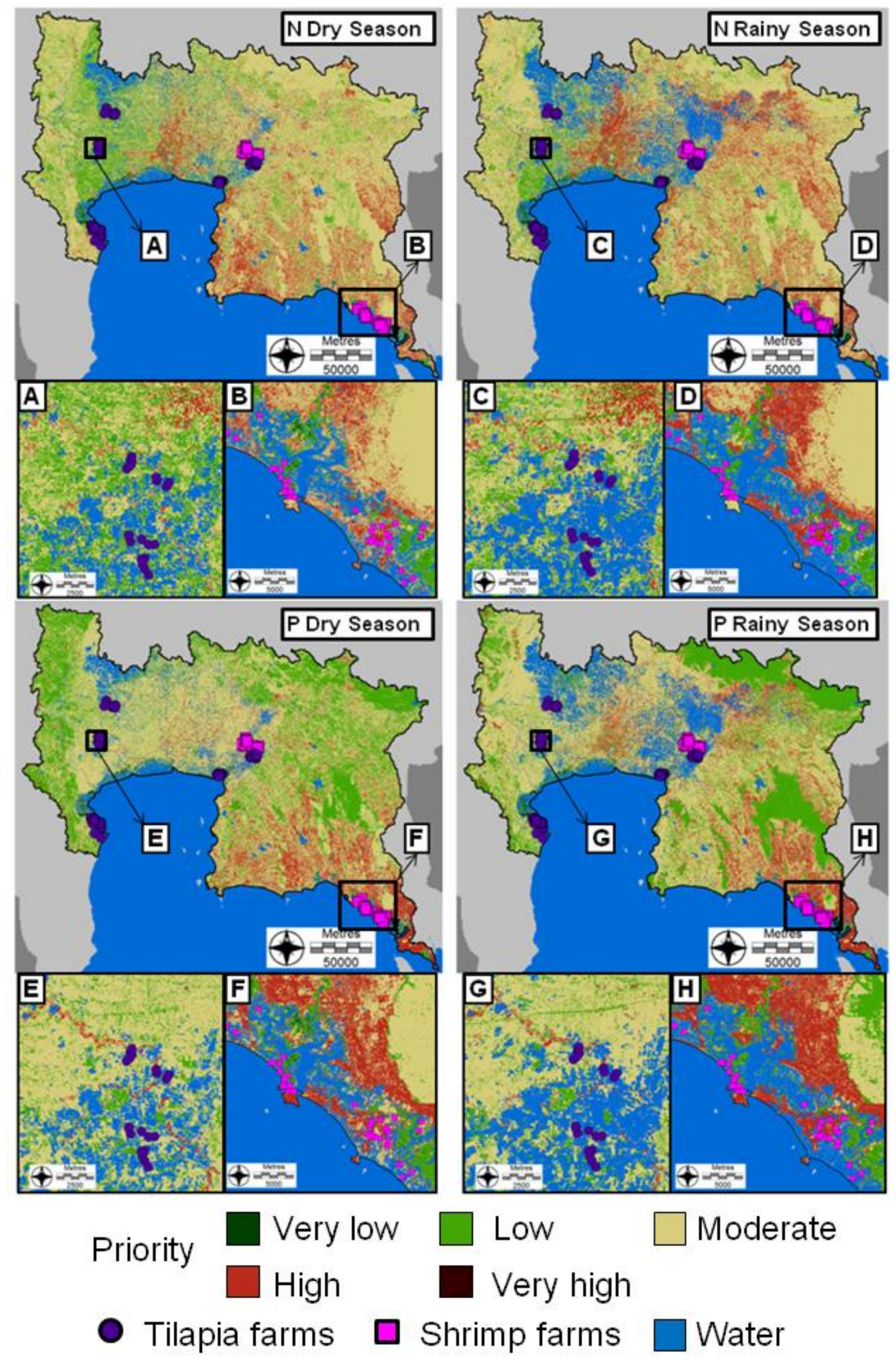

Figure 6: Results from the NPS models for the study area in Thailand. The tilapia and shrimp farms from the farmer survey are included for reference. The zoomed boxes show areas of interest for further inspection. 


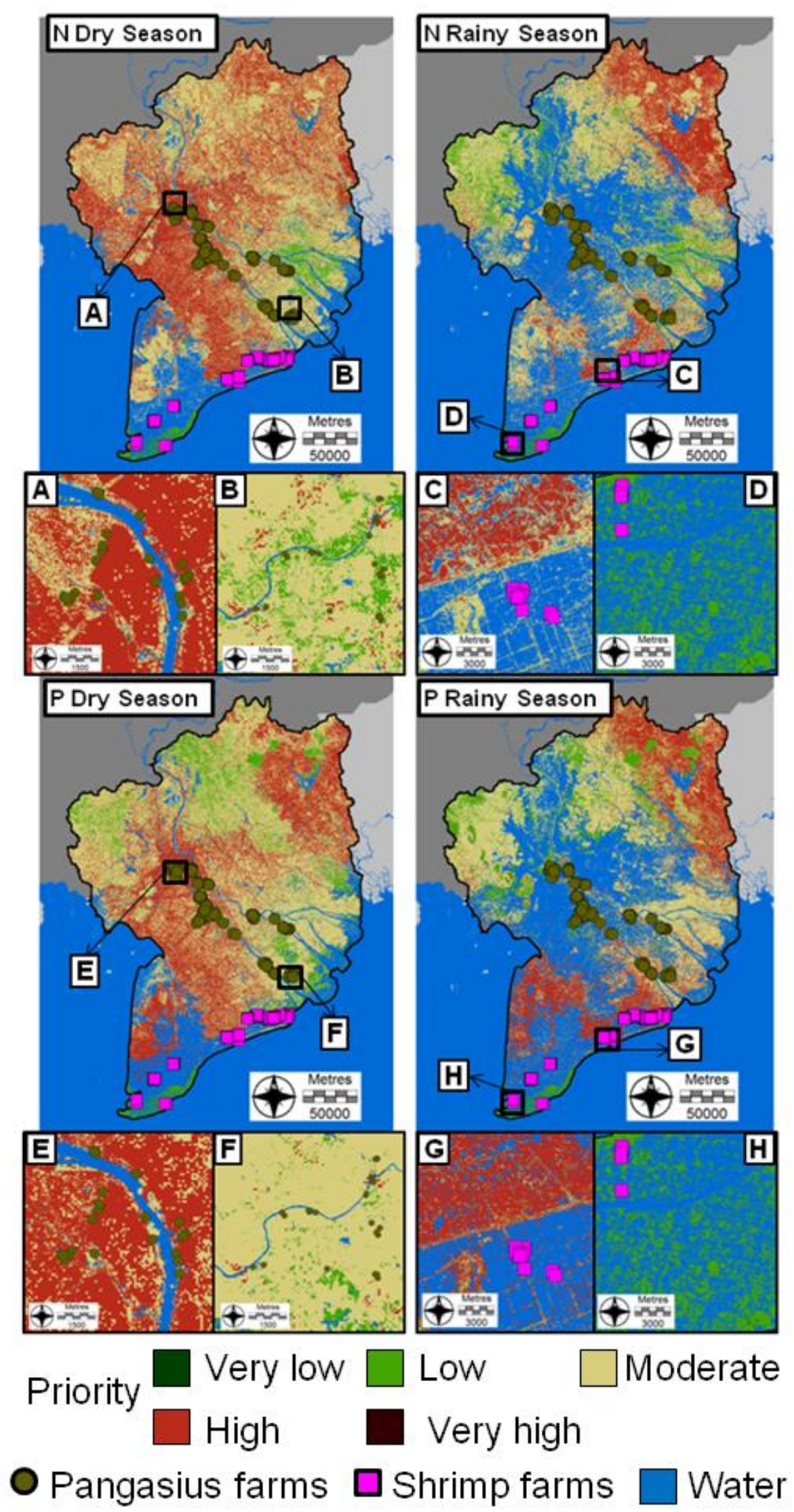

Figure 7: Results from the NPS models for the study area in Vietnam. The pangasius and shrimp farms from the farmer survey are included for reference. The zoomed boxes show areas of interest for further inspection. 
Table 1: Export coefficients assigned to each land use category

\begin{tabular}{|c|c|c|c|}
\hline \multirow[t]{2}{*}{ Land use type } & \multicolumn{2}{|c|}{$\begin{array}{l}\text { Export coefficient } \\
\left(\mathrm{t} / \mathrm{km}^{2} / \mathrm{yr}\right)\end{array}$} & \multirow[t]{2}{*}{ References } \\
\hline & Nitrogen & Phosphorus & \\
\hline Forest & 0.250 & 0.015 & Ma. (2011) \\
\hline $\begin{array}{l}\text { Trees / heavy } \\
\text { vegetation/ orchards }\end{array}$ & 0.180 & 0.520 & Ma. (2011) \\
\hline Grassland / shrubland & 0.600 & 0.080 & Ma. (2011) \\
\hline Bare ground & Rainfall & Rainfall & Ma. (2011) \\
\hline Agriculture & 2.150 & 0.430 & Ma. (2011) \\
\hline Soil / light vegetation & 1.100 & 0.020 & Ma. (2011) \\
\hline Mangroves & 0 & 0 & $\begin{array}{l}\text { Alongi (1996); Rivera- } \\
\text { Monroy et al., (1999); } \\
\text { Wösten et al. (2003) }\end{array}$ \\
\hline Town/city & 1.300 & 0.180 & Ma. (2011) \\
\hline
\end{tabular}


Table 2: Curve numbers $\left(\mathrm{CN}_{2}\right)$ for the different land use categories and hydrological soil groups $(A-$ low runoff potential, $B$ - moderately low runoff potential, $C$ - moderately high runoff potential, D - high runoff potential)

\begin{tabular}{lcccc}
\hline Land use type & \multicolumn{5}{c}{ Curve numbers for hydrological soil } \\
& A & B & C & D \\
& 25 & 55 & 70 & 77 \\
\hline Forest & 40 & 62 & 76 & 82 \\
Trees/heavy vegetation/orchard & 36 & 60 & 74 & 80 \\
Grassland/shrubland & 98 & 98 & 98 & 98 \\
Bare ground & 67 & 78 & 85 & 89 \\
Agriculture & 72 & 82 & 88 & 90 \\
Soil/ light vegetation & 32 & 58 & 72 & 79 \\
Mangroves & 90 & 93 & 94 & 95 \\
Town/City & & & & \\
\hline
\end{tabular}


Table 3: Areas $\left(\mathrm{km}^{2}\right.$ and \%) for each monitoring priority category for the NPS models

\begin{tabular}{|c|c|c|c|c|c|c|c|c|c|c|c|c|c|c|c|c|c|}
\hline \multirow{3}{*}{ Category } & \multirow{3}{*}{ Area } & \multicolumn{4}{|c|}{ Bangladesh } & \multicolumn{4}{|c|}{ China } & \multicolumn{4}{|c|}{ Thailand } & \multicolumn{4}{|c|}{ Vietnam } \\
\hline & & \multicolumn{2}{|c|}{ Dry season } & \multicolumn{2}{|c|}{ Rainy season } & \multicolumn{2}{|c|}{ Dry season } & \multicolumn{2}{|c|}{ Rainy season } & \multicolumn{2}{|c|}{ Dry season } & \multicolumn{2}{|c|}{ Rainy season } & \multicolumn{2}{|c|}{ Dry season } & \multicolumn{2}{|c|}{ Rainy season } \\
\hline & & $\mathbf{N}$ & $\mathbf{P}$ & $\mathbf{N}$ & $\mathbf{P}$ & $\mathbf{N}$ & $\mathbf{P}$ & $\mathbf{N}$ & $\mathbf{P}$ & $\mathbf{N}$ & $\mathbf{P}$ & $\mathbf{N}$ & $\mathbf{P}$ & $\mathbf{N}$ & $\mathbf{P}$ & $\mathbf{N}$ & $\mathbf{P}$ \\
\hline & $\mathbf{k m}^{2}$ & 1900 & 1900 & 3300 & 3300 & 800 & 800 & 1500 & 1500 & 3300 & 3300 & 6100 & 6100 & 10100 & 10100 & 25200 & 25200 \\
\hline Water & $\%$ & 19 & 19 & 32 & 32 & 3 & 3 & 6 & 6 & 7 & 7 & 13 & 13 & 15 & 15 & 38 & 38 \\
\hline \multirow{2}{*}{$\begin{array}{l}\text { Very low } \\
\text { priority }\end{array}$} & $\mathbf{k m}^{2}$ & 600 & 600 & 300 & 300 & 100 & 100 & $<1$ & $<1$ & 200 & 200 & 200 & 200 & 200 & 200 & 100 & 100 \\
\hline & $\%$ & 6 & 6 & 3 & 3 & $<1$ & $<1$ & $<1$ & $<1$ & $<1$ & $<1$ & $<1$ & $<1$ & $<1$ & $<1$ & $<1$ & $<1$ \\
\hline \multirow{2}{*}{$\begin{array}{l}\text { Low } \\
\text { priority }\end{array}$} & $\mathbf{k m}^{2}$ & 1200 & 1100 & 1700 & 1300 & 900 & 3100 & 400 & 1900 & 7400 & 13800 & 5300 & 11800 & 2900 & 6000 & 5700 & 6000 \\
\hline & $\%$ & 12 & 11 & 17 & 13 & 3 & 12 & 2 & 7 & 15 & 29 & 11 & 24 & 4 & 9 & 9 & 9 \\
\hline \multirow{2}{*}{$\begin{array}{c}\text { Moderate } \\
\text { priority }\end{array}$} & $\mathbf{k m}^{2}$ & 4400 & 4000 & 4000 & 4200 & 12600 & 14800 & 10100 & 10200 & 31500 & 26000 & 29300 & 24100 & 31000 & 31600 & 24400 & 21900 \\
\hline & $\%$ & 44 & 40 & 39 & 41 & 48 & 56 & 39 & 39 & 65 & 54 & 61 & 50 & 47 & 48 & 37 & 33 \\
\hline \multirow{2}{*}{$\begin{array}{l}\text { High } \\
\text { priority }\end{array}$} & $\mathbf{k m}^{2}$ & 2000 & 2500 & 900 & 1100 & 11700 & 7400 & 14200 & 12600 & 5900 & 5100 & 7500 & 6100 & 22200 & 18400 & 10800 & 13000 \\
\hline & $\%$ & 20 & 25 & 9 & 11 & 45 & 28 & 54 & 48 & 12 & 11 & 15 & 13 & 33 & 28 & 16 & 20 \\
\hline \multirow{2}{*}{$\begin{array}{l}\text { Very high } \\
\text { priority }\end{array}$} & $\mathbf{k m}^{2}$ & $<1$ & $<1$ & $<1$ & 0 & $<100$ & $<100$ & $<100$ & $<1$ & $<1$ & $<1$ & $<1$ & $<1$ & $<1$ & $<1$ & $<10$ & $<1$ \\
\hline & $\%$ & $<1$ & $<1$ & $<1$ & 0 & $<1$ & $<1$ & $<1$ & $<1$ & $<1$ & $<1$ & $<1$ & $<1$ & $<1$ & $<1$ & $<1$ & $<1$ \\
\hline
\end{tabular}

